\title{
Convective mixing fingers and chemistry interaction in carbon storage
}

Alvaro Sainz-Garcia ${ }^{(1-2)^{*}}$, Elena Abarca ${ }^{(1)}$, Albert Nardi $^{(1)}$, Fidel Grandia $^{(1)}$, Eric Oelkers $^{(2-3)}$

${ }^{1}$ Amphos 21 Consulting S.L., Passeig Garcia i Faria, 49-51, 08019, Barcelona, Spain.

${ }^{2}$ Université Toulouse III - Paul Sabatier, Route de Narbonne 118, 31062, Toulouse, France.

${ }^{3}$ Earth Science, University College London, Gower Street, NW1 OXG, London, United Kingdom.

${ }^{*}$ Corresponding author at: Amphos 21 Consulting S.L., Passeig Garcia i Faria, 49-51, 08019, Barcelona, Spain. Tel.: +34 9358305 00. Fax: +34 9330759 28. E-mail address: alvaro.sainz@amphos21.com

\section{Abstract}

Dissolution of carbon-dioxide into formation fluids during carbon capture and storage (CCS) can generate an instability with a denser $\mathrm{CO}_{2}$-rich fluid located above the less dense native aquifer fluid. This instability promotes convective mixing, enhancing $\mathrm{CO}_{2}$ dissolution and favouring the storage safety. Convective mixing has been extensively analysed in the context of CCS over the last decade, however the interaction between convective mixing and geochemistry has been insufficiently addressed. This relation is explored using a fully coupled model taking account the porosity and permeability variations due to dissolutionprecipitation reactions in a realistic geochemical system based on the Hontomín (Spain) potential CCS site project. This system, located in a calcite, dolomite, and gypsum bearing host rock, has been analyzed for a variety of Rayleigh and Damköhler values. Results show that chemical reactions tend to enhance $\mathrm{CO}_{2}$ dissolution. The model illustrates the first stages of porosity channel development, demonstrating the significance of fluid mixing in the development of porosity patterns. The influence of non-carbon species on $\mathrm{CO}_{2}$ dissolution shown in this study demonstrates the needs for realistic chemical and kinetic models to ensure the precision of physical models to accurately represent the carbondioxide injection process. 


\section{Keywords}

$\mathrm{CO}_{2}$ storage, Convective mixing, $\mathrm{CO}_{2}$ dissolution, Reactive transport, Physico-chemical interaction 


\section{Introduction}

Carbon capture and storage (CCS) may be the most promising measure for mitigating anthropogenic greenhouse gas emissions (Boot-Handford et al., 2014; Chu, 2009; Edenhofer et al., 2014; Haszeldine, 2009; Lackner, 2003; Metz et al., 2005; Oelkers and Cole, 2008). A likely storage host for much of this $\mathrm{CO}_{2}$ is deep saline aquifers, as they are widely distributed around the globe and have a large potential storage capacity (Bachu, 2003; Bradshaw et al., 2007; Firoozabadi and Cheng, 2010; Metz et al., 2005; Michael et al., 2010; Orr Jr, 2009; Szulczewski et al., 2012).

The target formations for subsurface geological storage are usually selected to preserve $\mathrm{CO}_{2}$ in a supercritical state. Supercritical carbon dioxide is commonly less dense and viscous than the surrounding native formation fluid and migrates upwards until it reaches an impervious caprock. Once at this caprock, supercritical $\mathrm{CO}_{2}$ spreads laterally. During its migration, some $\mathrm{CO}_{2}$ will dissolve into the fluid creating a transition zone. This $\mathrm{CO}_{2}$-rich aqueous fluid is approximately $1 \%$ denser than the native formation fluid (Ennis-King and Paterson, 2003; Garcia, 2001) and an instability arises, with a denser fluid located above the less dense native fluid. This instability promotes convection that carries the $\mathrm{CO}_{2}$-rich aqueous fluid downwards generating finger shape $\mathrm{CO}_{2}$-concentration profiles (Ennis-King and Paterson, 2003; Hidalgo et al., 2013; Kneafsey and Pruess, 2010).

$\mathrm{CO}_{2}$ dissolution is a key process for carbon storage. It increases storage safety by decreasing the $\mathrm{CO}_{2}$ fugacity, lowering the pressure of the supercritical $\mathrm{CO}_{2}$ and, thus, limiting the gas migration and pressure build up. Furthermore, dissolved $\mathrm{CO}_{2}$ promotes water-rock interaction that could mineralize the carbon, further increasing the stability of the carbon storage. As local thermodynamic equilibrium is rapidly attained between supercritical $\mathrm{CO}_{2}$ and the native formation fluid, its dissolution is controlled by the fluid 
renewal rate. Fluid convection, therefore, can increase dramatically the $\mathrm{CO}_{2}$ dissolution rate.

Recently, field evidence of these processes have been observed (Sathaye et al., 2014). Emami-Meybodi et al. (2015) reviewed recent advances in $\mathrm{CO}_{2}$ convective dissolution in saline aquifers through experiments, and theoretical and numerical models. Numerous studies have focused on the physical aspects of convection including the onset of instability and convection, effects of permeability variability, capillarity or aquifers natural flow (Emami-Meybodi et al., 2015; Hassanzadeh et al., 2007; Hidalgo et al., 2012; Hidalgo and Carrera, 2009; MacMinn et al., 2012; Meybodi and Hassanzadeh, 2013; Neufeld et al., 2010; Pau et al., 2010; Rapaka et al., 2008; Riaz et al., 2006; Slim and Ramakrishnan, 2010; Slim, 2014; Szulczewski and Juanes, 2013). However, much less is known about the interaction between convective mixing and geochemistry.

Although slow mineral-fluid reactions have little impact on gravitational instability, significant impact could be expected for fast reactions (Ennis-King and Paterson, 2007). A number of numerical analysis have assessed the effect of second order (Ghesmat et al., 2011) and first order (Andres and Cardoso, 2012, 2011) mineral carbonation reactions on convection in aquifers. Such reactions typically stabilize the system; Andres and Cardoso, (2012, 2011) determined a Damköhler-Rayleigh ratio above which convective mixing is not possible. Such behaviour has been studied in a steady-state regime (Ward et al., 2014), and extended to 1) anisotropic media (Hill and Morad, 2014), 2) a transient nonlinear case (Kim and Choi, 2014) and 3) using a Darcy-Brinkman formulation (Kim and Kim, 2015).

In a previous study, Cardoso and Andres (2014) showed theoretically and experimentally that natural convection can be retarded, or even inhibited, by chemical reactions in silicate-rich aquifers. In contrast, Loodts et al. (2014) found theoretically that the impact of chemical reactions on convection depends on the monotonicity of the densityconcentration profile in the system and showed experimentally that convective mixing is 
enhanced by the reaction of dissolved $\mathrm{CO}_{2}$ with $\mathrm{NaOH}$. These contrasting results emphasize the need to introduce realistic geochemical kinetics to accurately model the temporal evolution of carbon injection sites.

Alteration of the solid matrix due to mineral precipitation and dissolution may vary porosity, thereby altering the flow within an aquifer (Hewitt et al., 2013; Hidalgo et al., 2012). Fu et al. (2015) and Hidalgo et al. (2015) studied such interactions based on a mixing-limited reaction, assuming chemical equilibrium, and found that dissolution occurs in areas of high fluid mixing. Such effects are especially significant at flow stagnation points where the mixing layer is compressed and the transition between fluids with distinct compositions is shorter (Hidalgo et al., 2015).

This study explores numerically the interplay between geochemistry and convective mixing and its effect on $\mathrm{CO}_{2}$ solubility trapping in a potential industrial CCS project in northern Spain. A pilot $\mathrm{CO}_{2}$ geological storage project in deep saline aquifer is being coordinated by CIUDEN (CIUDad de la ENergía Foundation). The injection site is located in Hontomín (Burgos, Spain) within a carbonate-hosted aquifer, initially equilibrated with calcite, dolomite and gypsum. Calcite dissolution is assumed to follow a kinetic rate equation, whereas gypsum is assumed to react at local equilibrium. These reactions will alter fluid density, porosity, and permeability, and therefore the fluid flow patterns. This study builds upon similar efforts by Fu et al. (2015) and Hidalgo et al. (2015) by adding a more complex chemical system and showing the degree to which convective mixing can be enhanced by chemical reactions. Most notably, this study illuminates the effect of noncarbonate mineral reactions on $\mathrm{CO}_{2}$ dissolution in carbon storage. It demonstrates the need for a site specific geochemical assessment of potential CCS sites and the need to take specific account of all potential mineral-fluid reactions that may occur within the subsurface carbon storage system. The influence of Damköhler and Rayleigh numbers is 
illustrated, allowing the application of computed results to numerous other geologic storage sites.

\section{Model description}

\subsection{Physical governing equations}

The equations governing the hydrodynamic system are the conservative solute transport and the continuity equation of groundwater flow. The computational model uses the convective form of the solute transport equation, derived from the divergence form of the transport equation by subtracting fluid mass balance multiplied by solute concentration (Galeati and Gambolati, 1989; Goode, 1992; Saaltink et al., 2004) such that:

$\omega \frac{\partial \boldsymbol{c}}{\partial t}=-\psi \boldsymbol{q} \nabla \boldsymbol{c}+\nabla \cdot(\psi \boldsymbol{D} \nabla \boldsymbol{c})-\boldsymbol{c} \nabla \cdot \rho \boldsymbol{D} \nabla \omega^{w}$

$-\nabla \cdot(\rho \boldsymbol{q})=\rho S_{S} \frac{\partial p}{\partial t}$

where $\omega=\phi \rho \omega^{w}$ and $\psi=\rho \omega^{w}, \boldsymbol{c}$ refers to the concentration vector of all species, $\phi$ denotes the porosity, $\rho$ represents the liquid density, $\omega^{w}$ stands for the mass fraction of pure water in the liquid, $\boldsymbol{q}$ signifies the Darcy flow vector, $\boldsymbol{D}$ corresponds to the effective diffusion/dispersion tensor, which is assumed to be identical for all aqueous species, and $S_{S}$ designates the specific pressure storativity. Note that as $\boldsymbol{D}$ is assumed identical for all aqueous species, charge balance is preserved in the system.

Darcy flow is defined as:

$\boldsymbol{q}=-\frac{\kappa}{\mu}(\nabla p-\rho \boldsymbol{g})$

where $\kappa$ stands for the intrinsic permeability of the medium, $\mu$ denotes the dynamic viscosity, $p$ refers to the liquid pressure and $\boldsymbol{g}$ is the gravity acceleration. 
The model is coupled in two-ways; chemistry affects fluid flow and hydrodynamics influence chemical reactions. In our system the effect of non-carbon species on fluid density is negligible compared to that of dissolved inorganic carbon $\left(C^{T}\right.$ ) (Yang and $\mathrm{Gu}$, 2006). Density can be assumed, therefore, to be a linear function of local dissolved carbon concentration (considering all of the carbon aqueous species: $\mathrm{CO}_{2}^{(a q)}, \mathrm{HCO}_{3}^{-}$and $\mathrm{CO}_{3}^{-2}$ ) with an initial density $\left(\rho_{0}\right)$ and a compressibility factor $(\beta)$ in accord with

$\rho=\rho_{0}+\beta C^{T}$

The compressibility factor is based on that reported by Yang and Gu (2006) (Table 2) and results in a density difference between a $\mathrm{CO}_{2}$-free and a $\mathrm{CO}_{2}$-saturated fluid of $1 \%$ in accordance with previous studies (Garcia, 2001). Porosity depends on the mineral volumes of the media in accord with

$\phi=1-\phi_{\text {inert }}-\sum_{i}^{N_{m}} V_{m, i} c_{m, i}$

where $\phi_{\text {inert }}$ stands for the volume fraction of non-reactive minerals, $V_{m}$ refers to the molar volume of reactive mineral, and $c_{m}$ denotes the mineral concentration, expressed as moles of mineral per volume of porous medium, of each reactive mineral present in the aquifer. The permeability variation due to carbonate dissolution can be described using a power-law function of the porosity (Civan, 2001). Carroll et al. (2013) showed experimentally that the exponent for homogeneous carbonate rocks is 3 such that

$\kappa=\kappa_{0}\left(\phi / \phi_{0}\right)^{3}$,

In media where diffusion dominates over dispersion and with relative low tortuosity, effective diffusion can be described using the molecular diffusion coefficient $\left(D_{m}\right)$ times the porosity in accord with

$\boldsymbol{D}=D_{m} \boldsymbol{\phi}$, 


\subsection{The chemical system}

The chemical composition of the solid matrix and the fluid in the model are based on that of the pilot CCS injection site in Hontomín, Spain. The aquifer is composed of carbonate rocks hosted by a sulfate-rich fluid, in equilibrium with calcite $\left(\mathrm{CaCO}_{3}\right)$, dolomite $\left(\mathrm{CaMg}\left(\mathrm{CO}_{3}\right)_{2}\right)$ and gypsum $\left(\mathrm{CaSO}_{4} \cdot \mathrm{H}_{2} \mathrm{O}\right)$, at a temperature of $80{ }^{\circ} \mathrm{C}$ (Garcia-Rios et al., 2014). Dolomite is assumed to be unreactive in this model due to its slow dissolution rates compared to calcite (Pokrovsky et al., 2009). Gypsum rather than anhydrite precipitated in experiments performed with similar fluid composition and temperature (Garcia-Rios et al., 2014) so it has been included in the model.

Two end member fluids are considered to mix in the model calculation (Table 1): 1) the native formation fluid corresponding to that currently present in the Hontomín formation, CIUDEN pers. comm., 2011, and 2) a $\mathrm{CO}_{2}$-rich fluid obtained by equilibrating this native formation fluid with $\mathrm{CO}_{2}$ gas at a partial pressure of 50 atm. Thus, the concentrations of all species in these two fluids are identical except for its carbon content and $\mathrm{pH}$. The $\mathrm{CO}_{2}$-rich fluid has a higher density and lower $\mathrm{pH}$ than the native formation fluid. While the native formation fluid is in equilibrium with the rock, the acidic $\mathrm{CO}_{2}$-rich water will promote carbonate dissolution, increasing the rock permeability and potentially leading to the formation of wormhole-like flow structures (Fredd and Fogler, 1998; Hoefner and Fogler, 1988). Calcite dissolution will increase the aqueous fluid calcium concentration, which will promote gypsum precipitation. These aqueous phase reactions and mineral-fluid reactions are summarized below, together with their equilibrium constant ( $k$ for aqueous species) or solubility constant ( $k_{s p}$ for the mineral reactions).

$$
\begin{array}{ll}
\mathrm{CO}_{2}^{(a q)}+\mathrm{H}_{2} \mathrm{O} \leftrightarrow \mathrm{HCO}_{3}^{-}+H^{+}, & \log k=-6.35 \\
\mathrm{HCO}_{3}^{-} \leftrightarrow \mathrm{CO}_{3}^{-2}+H^{+}, & \log k=-10.33 \\
\mathrm{CaCO}_{3}+\mathrm{H}^{+} \leftrightarrow \mathrm{HCO}_{3}^{-}+\mathrm{Ca}^{2+}, & \log k_{s p}=1.85
\end{array}
$$




$$
\begin{array}{ll}
\mathrm{CaSO}_{4} \cdot 2 \mathrm{H}_{2} \mathrm{O} \leftrightarrow \mathrm{SO}_{4}^{2-}+\mathrm{Ca}^{2+}+2 \mathrm{H}_{2} \mathrm{O}, & \log k_{s p}=-4.48 \\
\mathrm{H}_{2} \mathrm{O} \leftrightarrow \mathrm{OH}^{-}+\mathrm{H}^{+}, & \log k_{w}=-14
\end{array}
$$

Thermodynamic data for the phases in reactions (8) to (12) were taken from the IInl.dat database (Delany and Lundeen, 1990). The activity coefficients are calculated following the B-dot equation (Helgeson, 1969) for all species except for aqueous carbon dioxide which activity is evaluated as a function of ionic strength based on the parameterization of Drummond, (1981).Gypsum precipitation is relatively fast and is assumed to occur at local equilibrium. In contrast, calcite dissolution has been modelled using the kinetic rate $(R)$ expression provided by Plummer et al. (1978):

$R=k_{r} a\left(m / m_{0}\right)^{\omega}\left(1-10^{S I_{\text {calcite }} 2 / 3}\right)$

where $k_{r}$ designates a rate constant, $a$ refers to the constant reactive surface area per mol of mineral, $S I_{\text {calcite }}$ stands for the saturation index of calcite, $\omega$ represents an exponential factor and $m$ and $m_{0}$ signify the mass of calcite per cubic meter of media currently and initially. Note that provision for calcite precipitation is not included in the modelled system. Although the Plummer et al. (1978) kinetic rate expression was developed for temperatures between $0-60{ }^{\circ} \mathrm{C}$ and $\mathrm{CO}_{2}$ pressures of $0-1 \mathrm{~atm}$, more recent calcite dissolution studies (Talman et al., 1990; Zhang et al., 2007) demonstrated its applicability at temperatures to at least $210{ }^{\circ} \mathrm{C}$. In addition, Pokrovsky et al. (2009) showed that $\mathrm{pH}$ is the main driver of calcite dissolution reaction rate in acidic fluids.

\subsection{Dimensionless parameters}

To generalize the results of this study, allowing its comparison and application to different scales and conditions, the computational results have been recast as functions of dimensionless parameters. Classically, convection due to gravity instabilities have been characterized using the Rayleigh number $(R a)$, which is the ratio between buoyancy and diffusion forces and given by 
$R a=\frac{\kappa \Delta \rho \boldsymbol{g} L_{z}}{\mu D_{m} \phi}$

where $\Delta \rho$ refers to the maximum density contrast between the end-member fluids and $L_{z}$ the characteristic length of the system, in this case the vertical extent of the domain. Systems with a high advective flow compared to diffusion have a high Rayleigh numbers. This will be the case for high permeable aquifers like the Sleipner (Bickle et al., 2007) that would have, for the same conditions as this model, a Rayleigh number of approximately 3700. In contrast, the less permeable layers of the Mount Simon sandstone (Zuo et al., 2012) would have a Rayleigh number of around 70.

The Damköhler number $(D a)$ expresses the ratio between reaction and diffusion rates and will be used to characterise the reactivity in the model:

$D a=\frac{k_{r} a L_{Z}^{2}}{D_{m} \phi^{\prime}}$

A high Damköhler number indicates a system with high reactivity. Such can be due to the occurrence of fast reactions (e.g. a limestone mostly composed by calcite will have higher $D a$ than a dolostone) or to the presence of minerals having a high reactive surface area.

\subsection{Numerical modelling}

The numerical model consists of a homogeneous two dimensional domain initially filled with the native formation fluid overlaid by the $\mathrm{CO}_{2}$-rich fluid (Fig. 1). The system initially has hydrostatic pressure conditions and no flow is allowed through its boundaries. No mass transfer occurs through the lateral and bottom boundaries. The presence of a constant, fixed carbon concentration in the top of the domain is assumed, neglecting potential effects of crossflow between the native brine and supercritical $\mathrm{CO}_{2}$ and resulting volume changes (Emami-Meybodi and Hassanzadeh, 2015; Hidalgo and Carrera, 2009). This assumption can increase the onset of convection time and reduce the rate of $\mathrm{CO}_{2}$ dissolution. In this study the dissolution rate of supercritical $\mathrm{CO}_{2}$ into the native formation 
fluid is assumed sufficiently fast to ensure the presence of a constantly saturated fluid at the native formation fluid/supercritical $\mathrm{CO}_{2}$ interface. A small fluctuation (standard deviation of 0.003 ) on the fixed carbon concentration in this top boundary layer was introduced to trigger instability. This small perturbation favours development of convective flow without significantly influencing the computed results (Pau et al., 2010).

The physico-chemical parameters of the model correspond closely to that of the Hontomín formation (Garcia-Rios et al., 2014); CIUDEN pers. comm., 2011 (Table 2). The Hontomín aquifer is composed of carbonate rocks. It is assumed that only $5 \%$ of the total aquifer volume consists of reactive calcite. Low values of the specific surface area were chosen to evaluate the far from equilibrium evolution of the system and may be consistent with industrial CCS applications due to the discrepancy between theoretical kinetic rates and the rates measured on field sites (Garcia-Rios et al., 2014; Kampman et al., 2014). A set of hydrodynamic and geochemical conditions was simulated for various Rayleigh and Damköhler values as summarized in Table 3.

A model domain $10 \mathrm{~m}$ length by $5 \mathrm{~m}$ depth (see Fig. 1) was chosen to be large enough to avoid boundary effects in both vertical and horizontal dimensions. A quadratic grid of 32,500 elements with a refinement in the upper layers was used in all simulations, while the total simulation time and the time steps were adapted depending on the velocity of the developed convective fingers. The total simulation time varies from 1 to 6 years and the time step varied from $1 \times 10^{5}$ to $5 \times 10^{5}$ seconds. The spatial and temporal discretization was chosen following stability and accuracy criteria such Peclet and Courant numbers. Furthermore, sensitivity analysis on both time and spatial discretization were performed.

The coupling between fluid flow and geochemistry was performed using iCP (interface COMSOL-PHREEQC), a platform for the simulation of complex THCM (Thermo-HydroChemical-Mechanical) problems (Nardi et al., 2014). It articulates two codes, the geochemical software PHREEQC (Parkhurst and Appelo, 2013) and the multiphysics 
software COMSOL (Multiphysics, 2013). The reactive transport equations are solved with a sequential non-iterative approach (SNIA) (Saaltink et al., 2001, 2000; Yeh and Tripathi, 1989). The conservative solute transport is computed in the first step with COMSOL while geochemistry is solved in a second step in PHREEQC. Compared with an iterative scheme, the SNIA does not pose global convergence problems although a tight control on the time step is required to minimize operator-splitting errors (Barry et al., 1996; Carrayrou et al., 2004; Jacques et al., 2006).

\section{Results}

\subsection{Convective mixing}

The modelled hydrodynamics is consistent with previous models of subsurface carbon injections (Hidalgo and Carrera, 2009; Kneafsey and Pruess, 2010; Riaz et al., 2006; Slim, 2014). Initially $\mathrm{CO}_{2}$ penetrates the native formation fluid by diffusion, creating a diffusive boundary layer (Fig. 2a). With time, the density at this boundary layer increases generating instabilities, triggering convection, and creating fingers (Fig. 2b,c). These fingers merge to form larger fingers creating a more complex convective flow pattern with denser fingers migrating downwards, while the less dense native formation fluid migrates upwards. When the native formation fluid reaches the upper boundary, the upward flow turns and progresses horizontally, generating new fingers. The horizontal stream of less dense native formation fluid pushes the newly formed fingers until they coalesce with more developed fingers. A narrowing of the well-developed fingers is also observed (Fig. 2d). Well-developed fingers move rapidly downwards, creating highly concentrated areas that may, eventually, separate from the main body of the finger (Fig. 2e).

Convective mixing significantly affects the dissolution of supercritical $\mathrm{CO}_{2}$ into the native fluid. The amount of supercritical $\mathrm{CO}_{2}$ dissolved can be quantified through the averaged 
mass flux of dissolved carbon dioxide $\left(\mathrm{CO}_{2}^{T}\right)$ per meter of aquifer lateral extent $\left(Q_{\mathrm{CO}_{2}}\right)$ such that

$Q_{C O_{2}}=\frac{1}{L_{x}} \iint \frac{\partial\left(C O_{2}^{T} \rho \phi \omega^{w}\right)}{\partial t} d x d y$

The carbon dioxide dissolution flux curves show the regimes of convection described previously (Fig 3). The dissolution of $\mathrm{CO}_{2}$ initially occurs only by molecular diffusion into the fluid phase (the pure diffusive flux curve is drawn in black in Fig 3 ). When instabilities appear, convective mixing is triggered and the $\mathrm{CO}_{2}$ dissolution flux increases abruptly. This flux reaches its maximum followed by a minor drop, with same slope as the diffusive flux, due to the merging of small fingers into larger fingers. Finally, the dissolution flux stabilizes at a much higher value than for the pure diffusive process.

Onset time of convection $\left(t_{C}\right)$ is a term used to quantify the transition point between diffusive to convective flux regime. Different definitions have been used in the literature (Pau et al., 2010; Pruess, 2008). In this study $t_{C}$ will be defined as the minimum in the $\mathrm{CO}_{2}$ dissolution flux curve (Hidalgo and Carrera, 2009). The time of convection onset and the $\mathrm{CO}_{2}$ dissolution fluxes of the simulated cases are grouped by their Rayleigh number (Fig 3), showing that dissolution is convection dominated. The higher the $R a$, the faster the onset time of convection and the higher $\mathrm{CO}_{2}$ dissolution rate. For simulations having equal $\mathrm{Da}$ number, the maximum dissolution flux increases linearly with the Rayleigh number. There is also an influence of geochemistry. The higher the reactivity of the system, the higher the $\mathrm{CO}_{2}$ flux into the fluid phase for same $\mathrm{Ra}$ number.

\subsection{Effects of Chemical Reactions}

The acidic $\mathrm{CO}_{2}$-rich fluid dissolves calcite, triggering chemical processes that alter the distribution of chemical species in the system. Carbon release due to calcite dissolution, leads to a higher concentration of dissolved carbon. In cases where the carbon concentration is close to its saturation limit this could diminish $\mathrm{CO}_{2}$ dissolution. In 
contrast, a higher dissolved carbon content generates a higher density gradient between the fluids, promoting enhanced convective mixing. In addition, calcite dissolution releases $\mathrm{Ca}^{2+}$ to the fluid leading to supersaturation and gypsum precipitation. Gypsum acts as a $\mathrm{Ca}^{2+}$ sink leading to faster calcite dissolution that, in turn, increases porosity and permeability of the aquifer, further enhancing the $\mathrm{CO}_{2}$ dissolution flux. Gypsum precipitation consumes $\mathrm{SO}_{4}{ }^{2-}$ and water, which modifies the concentration of otherwise conservative species.

Convective mixing affects all reactions producing non-uniform patterns of calcite dissolution and gypsum precipitation, and a heterogeneous distribution of reactive solutes (e.g. Ca and S) and slight variations of non-reactive solute concentrations (e.g. Cl) (Fig. 4). Calcite dissolution, driven by the $\mathrm{pH}$, occurs mostly in the upper part of the domain. While dissolving, calcite buffers the acidic fingers, limiting the advance of the reactive low $\mathrm{pH}$ front. As can be seen in Fig. 4 and Fig. $6 \mathrm{c}$, the area where $\mathrm{pH}$ is at or below 5 is limited to the upper meter of the domain. The availability of calcite controls the $\mathrm{pH}$ of the fingers and, therefore, the calcite content is critical for the development of heterogeneous porosity and persistent flow patterns. The less calcite, the larger the porosity channels will be. In our model, calcite was not exhausted in any point and simulation and only the first stages of porosity channeling pattern are observed (Fig. 5).

Although porosity increase is most pronounced in the upper layer of the domain, finger shaped dissolution patterns are evident in the lower parts of the aquifer as well (Fig. 5). Dissolution is concentrated at the finger margins and not at the tip or in the interior, as illustrated by the tip splitting of porosity development in Fig. 5. This result illustrates the role of fluid mixing in the reactions and is consistent with previous studies (Fu et al., 2015; Hidalgo et al., 2015). Most dissolution occurs where the concentration gradient is perpendicular to the flow direction and not where the flow and the concentration gradient are parallel. Porosity development or reduction is driven by aquifer 
geochemistry. The patterns of porosity changes depend on the aqueous fluid composition, the amount and distribution of reactive minerals, and their reaction rates. The locations of the maximum chemical reaction rates are, however, dominated by fluid mixing and, thus, porosity variations are expected to be observed at similar locations for different geochemical systems.

Note that in this study porosity development is moderated by gypsum precipitation. As the molar volume of gypsum $\left(0.07431 \mathrm{I} \cdot \mathrm{mol}^{-1}\right)$ is double that of calcite $\left(0.03693 \mathrm{I} \cdot \mathrm{mol}^{-1}\right)$, gypsum precipitation has a significant effect on the porosity and permeability, causing porosity reduction in some parts of the aquifer (Fig. 5). Similar to calcite dissolution, gypsum precipitation occurs in the areas of higher fluid mixing.

To gain insight into the interaction between geochemistry and convective mixing, the vertical profiles of density variation, porosity, $\mathrm{pH}$ and aqueous sulphur after one year of simulation are shown for cases performed using equal high Rayleigh numbers but different calcite reactivities (Fig. 6). The conservative case (no chemical reactions considered, RaH-Cons) and the case with low Damköhler number (RaH-DaL) yield almost identical results. Likewise, the case with high $\mathrm{Da}(\mathrm{RaH}-\mathrm{DaH})$ has a similar behaviour as that obtained assuming local fluid-calcite equilibrium (RaH-Eq). While the vertical profiles of the medium Damköhler case (RaH-DaM) are located between these two extremes. This trend is evident in the inset of Fig. $6 a$, where cases with higher $D a$ show a larger finger penetration into the aquifer.

In this chemical system, reactivity enhances convection (Fig. 6a). A higher dissolved carbon content due to calcite dissolution promotes a higher density contrast leading to a stronger convection and a deeper finger penetration. The influence of mineral reactivity is most evident in the $\mathrm{pH}$ and sulphur profiles. Cases with higher calcite reactivity better buffer the acidic $\mathrm{pH}$ front (Fig. 6c) and release more $\mathrm{Ca}^{2+}$. The abundance of calcium promotes gypsum precipitation and, thus, decreases aqueous sulphur concentrations (Fig. 6d). The 
increase of gypsum precipitation rates for cases of high calcite reactivity is also evidenced by a slight reduction of porosity $8 \mathrm{~cm}$ below the upper limit of the domain (Fig. $6 \mathrm{~b}$ ). Nevertheless, fast calcite dissolution rates lead to a higher porosity development overall.

To further characterize mineral phase evolution, the average calcite dissolution and gypsum precipitation rates were evaluated over the whole domain. The influence of the Damköhler number on calcite dissolution rates can be seen in Fig. 7a. Simulations with low Da number show almost no dissolution, while simulations performed using a medium $D a$ generated rates below $1.8 \times 10^{-8}\left(\mathrm{~mol} \cdot \mathrm{m}^{-2} \cdot \mathrm{s}^{-1}\right)$. High Da numbers result in calcite dissolution rates that are twice that of the medium $D a$ simulations, except in the case of low Rayleigh number (RaL-DaH) due to the longer times required for the onset of convection in the simulation. Dissolution rates tend to increase with time in all the simulations, although some fluctuations occur after the onset of convective flow (Fig. 7a). Simulations with high Da show an initial drop in the dissolution rate, indicating that calcite dissolution is limited by carbon dioxide diffusion into the aquifer for the cases with higher chemical potential. The influence of convective flow is evidenced by the quantity of calcite dissolution when increasing Ra number for an equal chemical potential.

The driving force for gypsum precipitation is the increased $\mathrm{Ca}^{2+}$ concentration stemming from calcite dissolution. Gypsum precipitation is, consequently, linearly related to calcite dissolution (Fig. 7b). Gypsum is in local equilibrium, but the gypsum precipitation rate is one order of magnitude lower than the calcite dissolution rate. Therefore, a net porosity increase is observed.

\subsection{Controlling parameters}

Onset time of convection $\left(t_{C}\right)$ shows a clear relation with $\sim 1 / R a^{2}$ (Fig. 8c). Riaz et al. (2006) demonstrated that $t_{C}$ scales with $t_{C} \sim \phi \mu^{2} D_{m} /(\kappa \Delta \rho \boldsymbol{g})^{2}$. This term can be rewritten in terms of the Rayleigh number $(R a)$ as: $t_{C} \sim L_{z}^{2} / R a^{2} D_{m} \phi$. Time of convection onset depends, thus, not only on $1 / R a^{2}$; but also on the characteristic length, porosity and 
diffusion. This relation is not obvious in Fig. $8 \mathrm{c}$ because in this model $R a$ has been varied without modifying $L_{z}, D_{m}$ and $\phi$.

The total amount of carbon dissolved and the maximum downward penetration depth of the fingers also illustrate the relevance of the Rayleigh number on the system (Fig. 8a,b). Both are linearly related to the $R a$ number and little impact of the chemical reactions is observed. However, a system with a higher reactivity (high Damköhler number) accelerates convection, leading to shorter convection onset times, enhanced $\mathrm{CO}_{2}$ dissolution, and longer fingers.

Porosity development is driven by both physical and chemical processes (Fig. 8d). Simulations with developed convective mixing after one year (Rayleigh numbers of 1800 and 3600) demonstrate that porosity is controlled by mineral dissolution/precipitation reactions, with similar porosity values for equal $D a$ numbers. While simulations with lower $R a$ exhibit a lower porosity development, independently of their $D a$. This can be due to the retardation of the onset of convection. Before convection fluid mixing is low and, therefore, little dissolution occurs.

\section{Conclusions}

The interaction between convective flow and geochemistry in a subsurface saline aquifer has been investigated using a coupled reactive transport model. The carbonate aquifer with a high aqueous sulphate content modelled in this study is representative of the natural Hontomín pilot CCS storage site and it is anticipated that the behavior calculated in this study may provide insight into other potential carbon storage aquifers.

As expected, fingering favors $\mathrm{CO}_{2}$ dissolution, leading to more stable storage and to a safer $\mathrm{CO}_{2}$ injection. Convective mixing is expected in CCS sites, although the time of onset will vary dramatically with the Rayleigh number of the aquifer. Once started, convective mixing will take place until the aqueous concentration of $\mathrm{CO}_{2}$ is homogenized throughout 
the aquifer. This depends on the width of the aquifer. Although the key driving force of convection and, thus of $\mathrm{CO}_{2}$ dissolution, is the Rayleigh number of the system, it is also influenced by chemical reactions. Contrary to previous studies with a single chemical reaction consuming carbon dioxide (Andres and Cardoso, 2012, 2011; Ghesmat et al., 2011), in the chemical system analysed in this study, the higher the mineral reaction rates, the faster the onset of convection; which in turns leads to higher $\mathrm{CO}_{2}$ dissolution rates.

Convective mixing leads to a heterogeneous distribution of aqueous species and nonuniform calcite dissolution and gypsum precipitation patterns. The simulations presented above illustrate the role of calcite as a buffer for acidic fluid fronts. Calcite dissolution restricts lower $\mathrm{pH}$ fluids to upper layers of the domain, where the majority of porosity development occurs. Besides, the degree of porosity development in the upper layer of the aquifer and at finger boundaries shows the relevance of fluid mixing in chemical reactions. Demonstrating that major reactivity occurs where concentration gradient is perpendicular to the flow direction.

The role of non-carbon minerals and species on the dissolution of $\mathrm{CO}_{2}$ is demonstrated to be significant. Although, gypsum precipitation reduces porosity and permeability, it also acts as a $\mathrm{Ca}^{2+}$ sink, leading to further calcite dissolution. Thus, gypsum precipitation generally enhances porosity development. This coupling between reactions and fluid flow are not obvious and demonstrate need for comprehensive flow models that includes a realistic description of the chemical system.

For the aquifer chemical composition of this study, a relatively accurate estimate of the $\mathrm{CO}_{2}$ dissolution rate could be obtained from the Rayleigh number of the system alone. This, however, depends on the specific conditions of each injection site. Coupled models to study the interaction between fluid flow and geochemistry would be needed to ensure the precision of physical models to accurately represent carbon-dioxide injection into subsurface storage sites. 


\section{Acknowledgment}

The research leading to these results has received funding from the CO2-REACT People Programme (Marie Curie Actions) of the European Union's Seventh Framework Programme FP7-2012-ITN under REA grant agreement $n^{\circ}$ 317235. Elena Abarca acknowledges the support of the Spanish Ministry of Science through the Torres Quevedo grant with reference PTQ-12-B60626447.

\section{References}

Andres, J.T.H., Cardoso, S.S.S., 2012. Convection and reaction in a diffusive boundary layer in a porous medium: Nonlinear dynamics. Chaos An Interdiscip. J. Nonlinear Sci. 22, 37113.

Andres, J.T.H., Cardoso, S.S.S., 2011. Onset of convection in a porous medium in the presence of chemical reaction. Phys. Rev. E 83, 46312.

Appelo, C.A.J., 2007. Multicomponent diffusion in clays. Water Pollut. Nat. Porous Media 3-13.

Bachu, S., 2003. Screening and ranking of sedimentary basins for sequestration of $\mathrm{CO}_{2}$ in geological media in response to climate change. Environ. Geol. 44, 277-289.

Barry, D.A., Miller, C.T., Culligan-Hensley, P.J., 1996. Temporal discretisation errors in noniterative split-operator approaches to solving chemical reaction/groundwater transport models. J. Contam. Hydrol. 22, 1-17.

Bickle, M., Chadwick, A., Huppert, H.E., Hallworth, M., Lyle, S., 2007. Modelling carbon dioxide accumulation at Sleipner: Implications for underground carbon storage. Earth Planet. Sci. Lett. 255, 164-176.

Boot-Handford, M.E., Abanades, J.C., Anthony, E.J., Blunt, M.J., Brandani, S., Mac Dowell, N., Fernandez, J.R., Ferrari, M.-C., Gross, R., Hallett, J.P., Haszeldine, R.S., Heptonstall, P., Lyngfelt, A., Makuch, Z., Mangano, E., Porter, R.T.J., Pourkashanian, M., Rochelle, G.T., Shah, N., Yao, J.G., Fennell, P.S., 2014. Carbon capture and storage update. Energy Environ. Sci. 7, 130-189. doi:10.1039/C3EE42350F

Bradshaw, J., Bachu, S., Bonijoly, D., Burruss, R., Holloway, S., Christensen, N.P., Mathiassen, O.M., 2007. $\mathrm{CO}_{2}$ storage capacity estimation: issues and development of standards. Int. J. Greenh. Gas Control 1, 62-68.

Cardoso, S.S.S., Andres, J.T.H., 2014. Geochemistry of silicate-rich rocks can curtail spreading of carbon dioxide in subsurface aquifers. Nat. Commun. 5, 5743.

Carrayrou, J., Mosé, R., Behra, P., 2004. Operator-splitting procedures for reactive transport and comparison of mass balance errors. J. Contam. Hydrol. 68, 239-268.

Carroll, S., Hao, Y., Smith, M., Sholokhova, Y., 2013. Development of scaling parameters to 
describe $\mathrm{CO}_{2}$-rock interactions within Weyburn-Midale carbonate flow units. Int. J. Greenh. Gas Control 16, S185--S193.

Chu, S., 2009. Carbon capture and sequestration. Science (80-. ). 325, 1599.

Civan, F., 2001. Scale effect on porosity and permeability: Kinetics, model, and correlation. AIChE J. 47, 271-287.

Delany, J.M., Lundeen, S.R., 1990. The LLNL thermochemical database. Lawrence Livermore Natl. Lab. Rep. UCRL-21658 150.

Drummond, S.E., 1981. Boiling and mixing of hydrothermal fluids: chemical effects on mineral precipitation. Pennsylvania State University.

Edenhofer, O., Pichs-Madruga, R., Sokona, Y., Farahani, E., Kadner, S., Seyboth, K., others, 2014. IPCC, Climate Change 2014: Mitigation of Climate Change (techreport). Cambridge University Press.

Emami-Meybodi, H., Hassanzadeh, H., 2015. Two-phase convective mixing under a buoyant plume of $\mathrm{CO}_{2}$ in deep saline aquifers. Adv. Water Resour. 76, 55-71.

Emami-Meybodi, H., Hassanzadeh, H., Green, C.P., Ennis-King, J., 2015. Convective dissolution of $\mathrm{CO}_{2}$ in saline aquifers: Progress in modeling and experiments. Int. J. Greenh. Gas Control 40, 238-266. doi:http://dx.doi.org/10.1016/j.ijggc.2015.04.003

Ennis-King, J., Paterson, L., 2007. Coupling of geochemical reactions and convective mixing in the long-term geological storage of carbon dioxide. Int. J. Greenh. Gas Control 1, 86-93.

Ennis-King, J., Paterson, L., 2003. Role of convective mixing in the long-term storage of carbon dioxide in deep saline formations, in: SPE Annual Technical Conference and Exhibition.

Firoozabadi, A., Cheng, P., 2010. Prospects for subsurface $\mathrm{CO}_{2}$ sequestration. AlChE J. 56, 1398-1405.

Fredd, C.N., Fogler, H.S., 1998. Influence of transport and reaction on wormhole formation in porous media. AIChE J. 44, 1933-1949. doi:10.1002/aic.690440902

Fu, X., Cueto-Felgueroso, L., Bolster, D., Juanes, R., 2015. Rock dissolution patterns and geochemical shutdown of-brine-carbonate reactions during convective mixing in porous media. J. Fluid Mech. 764, 296-315.

Galeati, G., Gambolati, G., 1989. On boundary conditions and point sources in the finite element integration of the transport equation. Water Resour. Res. 25, 847-856.

Garcia, J.E., 2001. Density of aqueous solutions of $\mathrm{CO}_{2}$, Lawrence Berkeley National Laboratory. Pap. LBNL-49023.

Garcia-Rios, M., Cama, J., Luquot, L., Soler, J.M., 2014. Interaction between $\mathrm{CO}_{2}$-rich sulfate solutions and carbonate reservoir rocks from atmospheric to supercritical $\mathrm{CO}_{2}$ conditions: Experiments and modeling. Chem. Geol. 383, 107-122. doi:http://dx.doi.org/10.1016/j.chemgeo.2014.06.004

Ghesmat, K., Hassanzadeh, H., Abedi, J., 2011. The impact of geochemistry on convective mixing in a gravitationally unstable diffusive boundary layer in porous media: $\mathrm{CO}_{2}$ 
storage in saline aquifers. J. Fluid Mech. 673, 480-512.

Goode, D.J., 1992. Modeling Transport in Transient Ground-Water Flow: An Unacknowledged Approximation. Ground Water 30, 257-261.

Hassanzadeh, H., Pooladi-Darvish, M., Keith, D.W., 2007. Scaling behavior of convective mixing, with application to geological storage of CO2. AIChE J. 53, 1121-31.

Haszeldine, R.S., 2009. Carbon capture and storage: how green can black be? Science (80-. ). 325, 1647-52.

Helgeson, H.C., 1969. Thermodynamics of hydrothermal systems at elevated temperatures and pressures. Am. J. Sci. 267, 729-804.

Hewitt, D.R., Neufeld, J.A., Lister, J.R., 2013. Convective shutdown in a porous medium at high Rayleigh number. J. Fluid Mech. 719, 551-586.

Hidalgo, J.J., Carrera, J., 2009. Effect of dispersion on the onset of convection during $\mathrm{CO}_{2}$ sequestration. J. Fluid Mech. 640, 441-452.

Hidalgo, J.J., Dentz, M., Cabeza, Y., Carrera, J., 2015. Dissolution patterns and mixing dynamics in unstable reactive flow. Geophys. Res. Lett. 42, 6357-6364.

Hidalgo, J.J., Fe, J., Cueto-Felgueroso, L., Juanes, R., 2012. Scaling of convective mixing in porous media. Phys. Rev. Lett. 109, 264503-264507.

Hidalgo, J.J., MacMinn, C.W., Juanes, R., 2013. Dynamics of convective dissolution from a migrating current of carbon dioxide. Adv. Water Resour. 62, 511-519.

Hill, A.A., Morad, M.R., 2014. Convective stability of carbon sequestration in anisotropic porous media, in: Proceedings of the Royal Society of London A: Mathematical, Physical and Engineering Sciences. p. 20140373.

Hoefner, M.L., Fogler, H.S., 1988. Pore evolution and channel formation during flow and reaction in porous media. AIChE J. 34, 45-54.

Jacques, D., Simunek, J., Mallants, D., Van Genuchten, M.T., 2006. Operator-splitting errors in coupled reactive transport codes for transient variably saturated flow and contaminant transport in layered soil profiles. J. Contam. Hydrol. 88, 197-218.

Kampman, N., Bickle, M., Wigley, M., Dubacq, B., 2014. Fluid flow and $\mathrm{CO}_{2}$-fluid-mineral interactions during $\mathrm{CO}_{2}$-storage in sedimentary basins. Chem. Geol. 369, 22-50.

Kim, M.C., Choi, C.K., 2014. Effect of first-order chemical reaction on gravitational instability in a porous medium. Phys. Rev. E 90, 53016.

Kim, M.C., Kim, Y.H., 2015. The effect of chemical reaction on the onset of gravitational instabilities in a fluid saturated within a vertical Hele-Shaw cell: Theoretical and numerical studies. Chem. Eng. Sci. 134, 632-647.

Kneafsey, T.J., Pruess, K., 2010. Laboratory flow experiments for visualizing carbon dioxide-induced, density-driven brine convection. Transp. Porous Media 82, 123-139.

Lackner, K.S., 2003. A guide to $\mathrm{CO}_{2}$ sequestration. Science (80-. ). 300, 1677-1678.

Loodts, V., Thomas, C., Rongy, L., De Wit, A., 2014. Control of convective dissolution by chemical reactions: general classification and application to $\mathrm{CO}_{2}$ dissolution in reactive aqueous solutions. Phys. Rev. Lett. 113, 114501. 
MacMinn, C.W., Neufeld, J.A., Hesse, M.A., Huppert, H.E., 2012. Spreading and convective dissolution of carbon dioxide in vertically confined, horizontal aquifers. Water Resour. Res. 48, 11516-11526.

Metz, B., Davidson, O., de Coninck, H., Loos, M., Meyer, L., others, 2005. IPCC special report on carbon dioxide capture and storage (techreport). Cambridge University Press.

Meybodi, H.-E., Hassanzadeh, H., 2013. Stability analysis of two-phase buoyancy-driven flow in the presence of a capillary transition zone. Phys. Rev. E 87, 33009. doi:10.1103/PhysRevE.87.033009

Michael, K., Golab, A., Shulakova, V., Ennis-King, J., Allinson, G., Sharma, S., Aiken, T., 2010. Geological storage of $\mathrm{CO} 2$ in saline aquifers - a review of the experience from existing storage operations. Int. J. Greenh. Gas Control 4, 659-667.

Multiphysics, C., 2013. COMSOL Multiphysics/Reference Manual Version 4.4. COMSOL AB, Stokholm, Sweden.

Nardi, A., Idiart, A., Trinchero, P., de Vries, L.M., Molinero., J., 2014. Interface COMSOLPHREEQC (iCP), an efficient numerical framework for the solution of coupled multiphysics and geochemistry. Comput. Geosci. 69, 10-21.

Neufeld, J.A., Hesse, M.A., Riaz, A., Hallworth, M.A., Tchelepi, H.A., Huppert, H.E., 2010. Convective dissolution of carbon dioxide in saline aquifers. Geophys. Res. Lett. 37.

Oelkers, E.H., Cole, D.R., 2008. Carbon dioxide sequestration a solution to a global problem. Elements 4, 305-310.

Orr Jr, F.M., 2009. $\mathrm{CO}_{2}$ capture and storage: are we ready? Energy Environ. Sci. 2, 449458.

Parkhurst, D.L., Appelo, C.A.J., 2013. Description of input and examples for PHREEQC version 3: a computer program for speciation, batch-reaction, one-dimensional transport, and inverse geochemical calculations (techreport).

Pau, G.S.H., Bell, J.B., Pruess, K., Almgren, A.S., Lijewski, M.J., Zhang, K., 2010. Highresolution simulation and characterization of density-driven flow in $\mathrm{CO}_{2}$ storage in saline aquifers. Adv. Water Resour. 33, 443-455.

Plummer, L., Wigley, T., Parkhurst, D., 1978. The Kinetics of Calcite Dissolution in CO2Water Systems at $5^{\circ}$ to $60^{\circ} \mathrm{C}$ and 0.0 to 1.0 ATM CO2. Am. J. Sci. 278, 179-216.

Pokrovsky, O.S., Golubev, S. V, Schott, J., Castillo, A., 2009. Calcite, dolomite and magnesite dissolution kinetics in aqueous solutions at acid to circumneutral $\mathrm{pH}, 25$ to $150{ }^{\circ} \mathrm{C}$ and 1 to 55 atm pCO2: New constraints on $\mathrm{CO} 2$ sequestration in sedimentary basins. Chem. Geol. 265, 20-32.

Pruess, K., 2008. Numerical modeling studies of the dissolution-diffusion-convection process during $\mathrm{CO}_{2}$ storage in saline aquifers. Lawrence Berkeley Natl. Lab.

Rapaka, S., Chen, S., Pawar, R.J., Stauffer, P.H., Zhang, D., 2008. Non-modal growth of perturbations in density-driven convection in porous media. J. Fluid Mech. 609, 285303. 
Riaz, A., Hesse, M., Tchelepi, H.A., Orr, F.M., 2006. Onset of convection in a gravitationally unstable diffusive boundary layer in porous media. J. Fluid Mech. 548, 87-111.

Saaltink, M.W., Carrera, J., Ayora, C., 2001. On the behavior of approaches to simulate reactive transport. J. Contam. Hydrol. 48, 213-235.

Saaltink, M.W., Carrera, J., Ayora, C., 2000. A comparison of two approaches for reactive transport modelling. J. Geochemical Explor. 69, 97-101.

Saaltink, M.W., Carrera, J., Olivella, S., 2004. Mass balance errors when solving the convective form of the transport equation in transient flow problems. Water Resour. Res. 40, W05107--1.

Sathaye, K.J., Hesse, M.A., Cassidy, M., Stockli, D.F., 2014. Constraints on the magnitude and rate of $\mathrm{CO}_{2}$ dissolution at Bravo Dome natural gas field. Proc. Natl. Acad. Sci. 111, 15332-15337.

Slim, A., Ramakrishnan, T., 2010. Onset and cessation of time-dependent, dissolutiondriven convection in porous media. Phys. Fluids 22, 1-11.

Slim, A.C., 2014. Solutal-convection regimes in a two-dimensional porous medium. J. Fluid Mech. 741, 461-491.

Szulczewski, M.L., Juanes, R., 2013. The evolution of miscible gravity currents in horizontal porous layers. J. Fluid Mech. 719, 82-96.

Szulczewski, M.L., MacMinn, C.W., Herzog, H.J., Juanes, R., 2012. Lifetime of carbon capture and storage as a climate-change mitigation technology. Proc. Natl. Acad. Sci. 109, 5185-5189.

Talman, S.J., Wiwchar, B., Gunter, W.D., Scarge, C.M., 1990. Dissolution kinetics of calcite in the $\mathrm{H}_{2} \mathrm{O}-\mathrm{CO}_{2}$ system along the steam saturation curve to $210 \mathrm{C}$. Fluid-Mineral Interact. A Tribut. to HP Eugster 41-55.

Ward, T.J., Cliffe, K.A., Jensen, O.E., Power, H., 2014. Dissolution-driven porous-medium convection in the presence of chemical reaction. J. Fluid Mech. 747, 316-349.

Yang, C., and Yongan $\mathrm{Gu}, 2006$. Accelerated mass transfer of $\mathrm{CO}_{2}$ in reservoir brine due to density-driven natural convection at high pressures and elevated temperatures. Ind. Eng. Chem. Res. 45, 2430-2436. doi:10.1021/ie050497r

Yeh, G.-T., Tripathi, V.S., 1989. A critical evaluation of recent developments in hydrogeochemical transport models of reactive multichemical components. Water Resour. Res. 25, 93-108.

Zhang, R., Hu, S., Zhang, X., Yu, W., 2007. Dissolution kinetics of dolomite in water at elevated temperatures. Aquat. Geochemistry 13, 309-338.

Zuo, L., Krevor, S., Falta, R.W., Benson, S.M., 2012. An experimental study of $\mathrm{CO}_{2}$ exsolution and relative permeability measurements during $\mathrm{CO}_{2}$ saturated water depressurization. Transp. porous media 91, 459-478. 


\section{Figures}

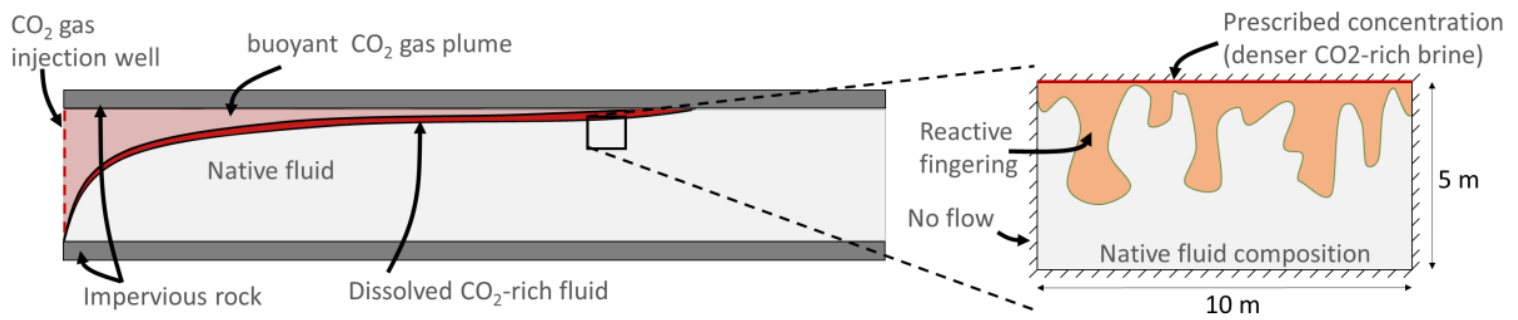

Fig. 1. Schematic illustration of the domain and boundary conditions considered in this study. The migration of supercritical $\mathrm{CO}_{2}$ as well as its dissolution in the native brine promotes the convective mixing of the fluids. 


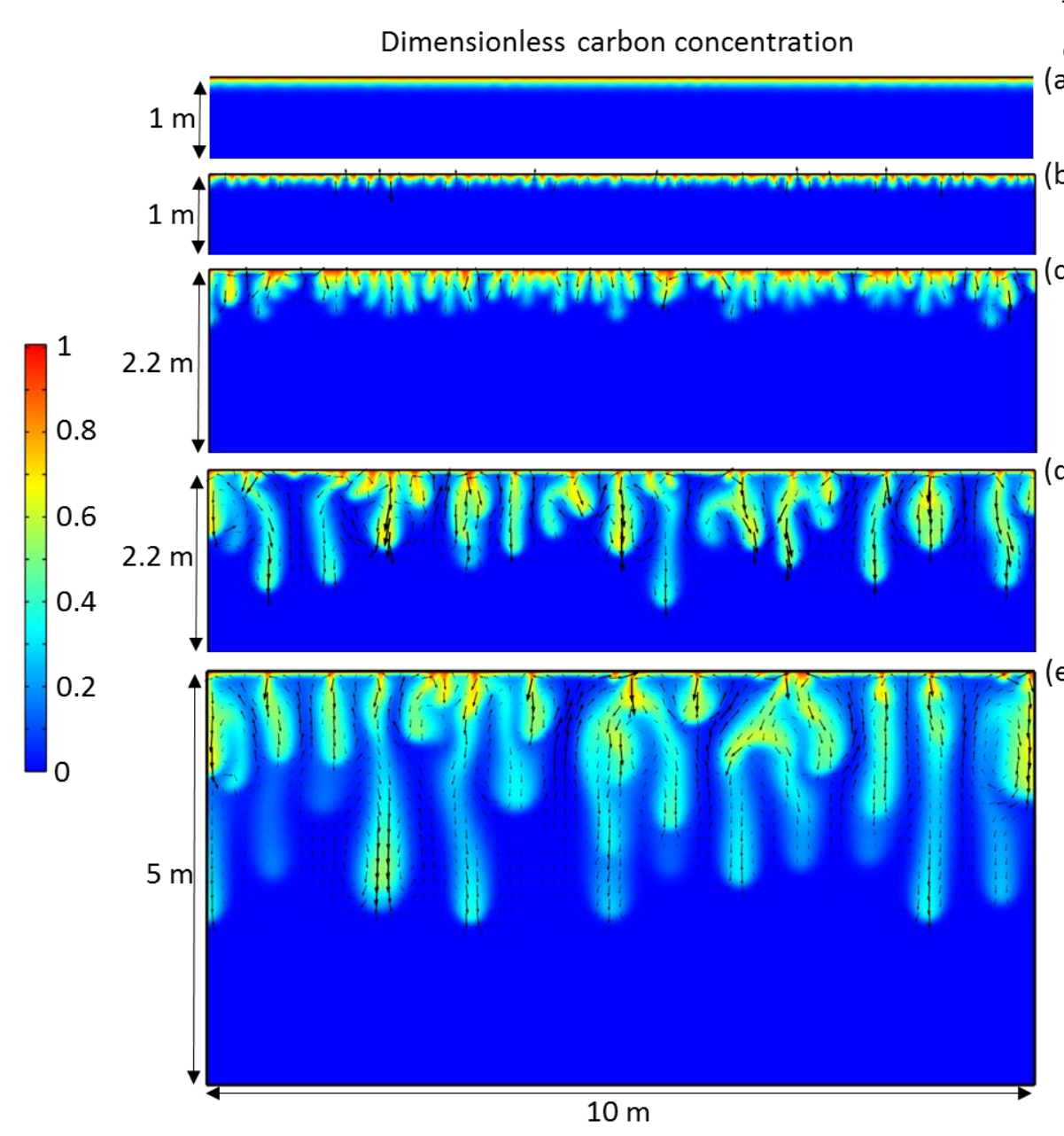

Transversal average carbon concentration (a)

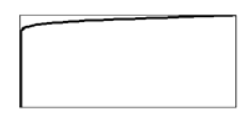

(b)

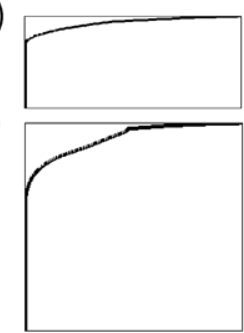

(d)

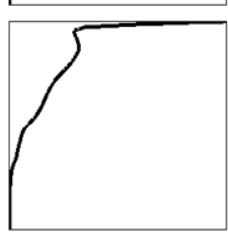

(e)

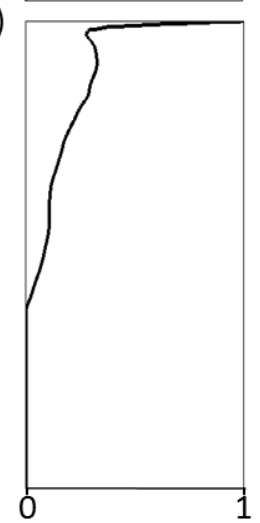

Fig. 2. Dimensionless carbon concentration (left) and horizontal average carbon concentration profiles (right) for times 0.05(a), 0.1(b), 0.25(c), 0.5(d) and 1(e) years of simulation with Rayleigh = 3600 and Damköhler $=9.21 \times 10^{6}(\mathrm{RaH}-\mathrm{DaM})$. Note the arrows illustrate the fluid velocity field. . Dimensionless carbon concentration is defined as: $C^{\prime}=\left(C^{T}-\right.$ $\left.C_{\max }^{T}\right) /\left(C_{\min }^{T}-C_{\max }^{T}\right)$; where $C_{\min }^{T}$ and $C_{\max }^{T}$ represent the minimum and maximum carbon concentration in the simulation. 


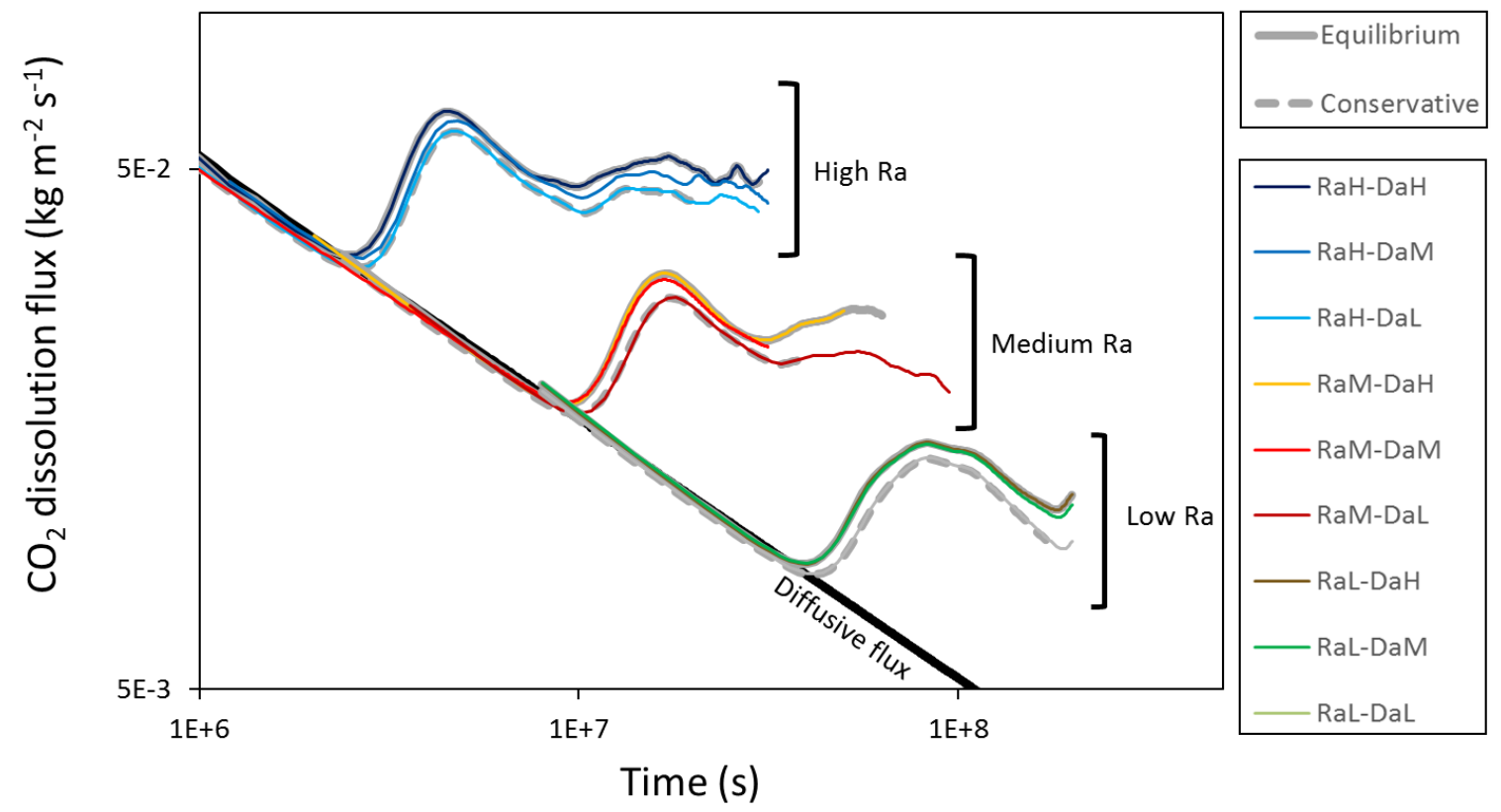

Fig 3. Comparison of averaged $\mathrm{CO}_{2}$ flux per meter of aquifer lateral extent for all simulations and compared to the pure diffusion flux. RaH, RaM and RaL refer to high, medium and low Rayleigh number; DaH, DaM and DaL mean high, medium and low Damköhler number- see Table 3. Conservative refers to simulations without chemical reactions and equilibrium refers to simulations assuming calcite is in equilibrium with the fluid phase. The results of DaH and DaL are similar to the equilibrium and conservative simulations, respectively and in some cases their curves overlap. Both axis are in logarithmic scale. 

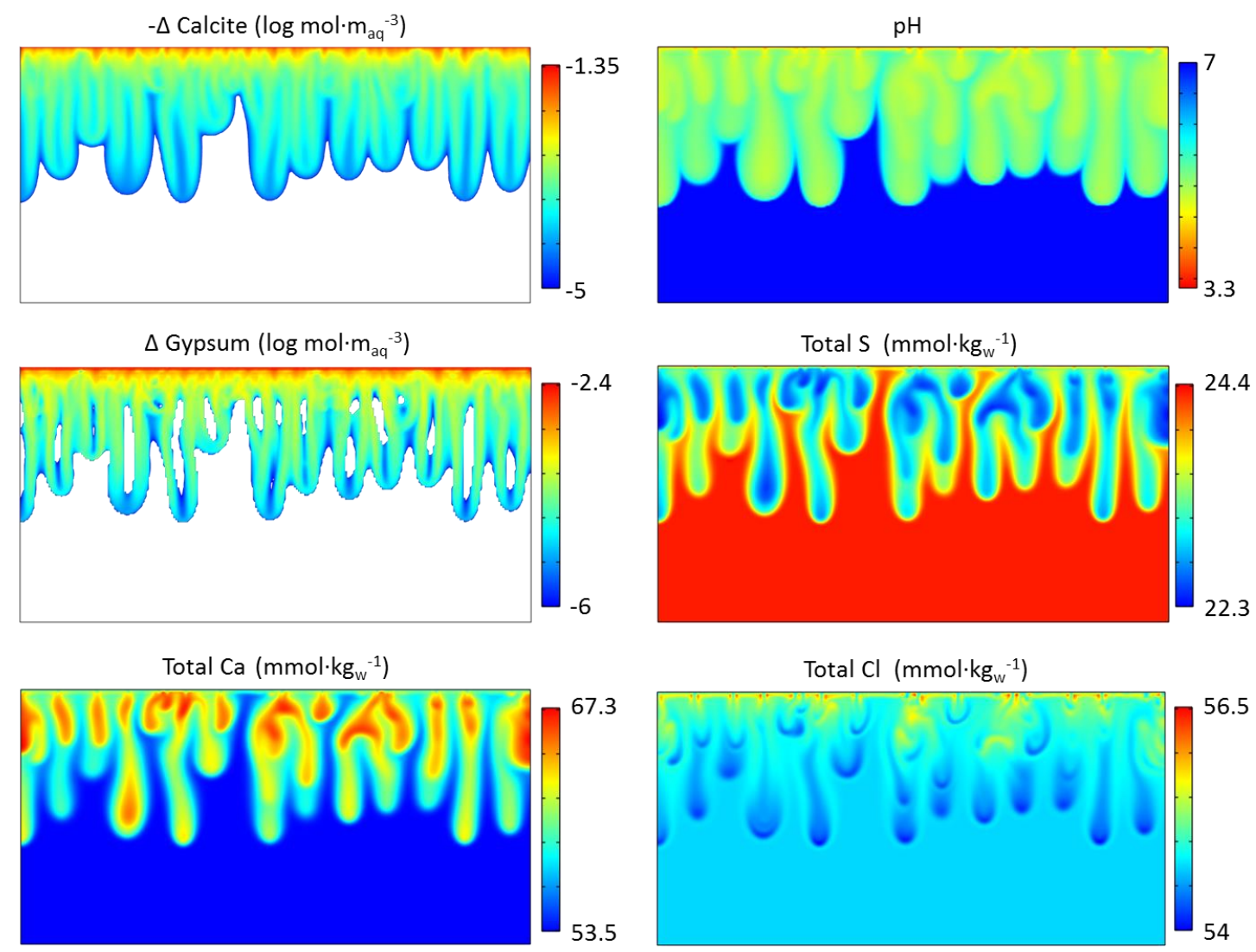

Fig. 4. Distribution of change in calcite content, change in gypsum content, $\mathrm{pH}$, calcium, sulphur and chlorine for the simulation with Rayleigh $=3600$ and Damköhler $=9.21 \times 10^{6}(\mathrm{RaH}-\mathrm{DaM})$ after one year. Note the different scales and units. The changes in mineral content is illustrated in $\mathrm{mol} \cdot \mathrm{m}^{-3}$ of aquifer and in log scale, areas with no change in mineral content are shown in white. 


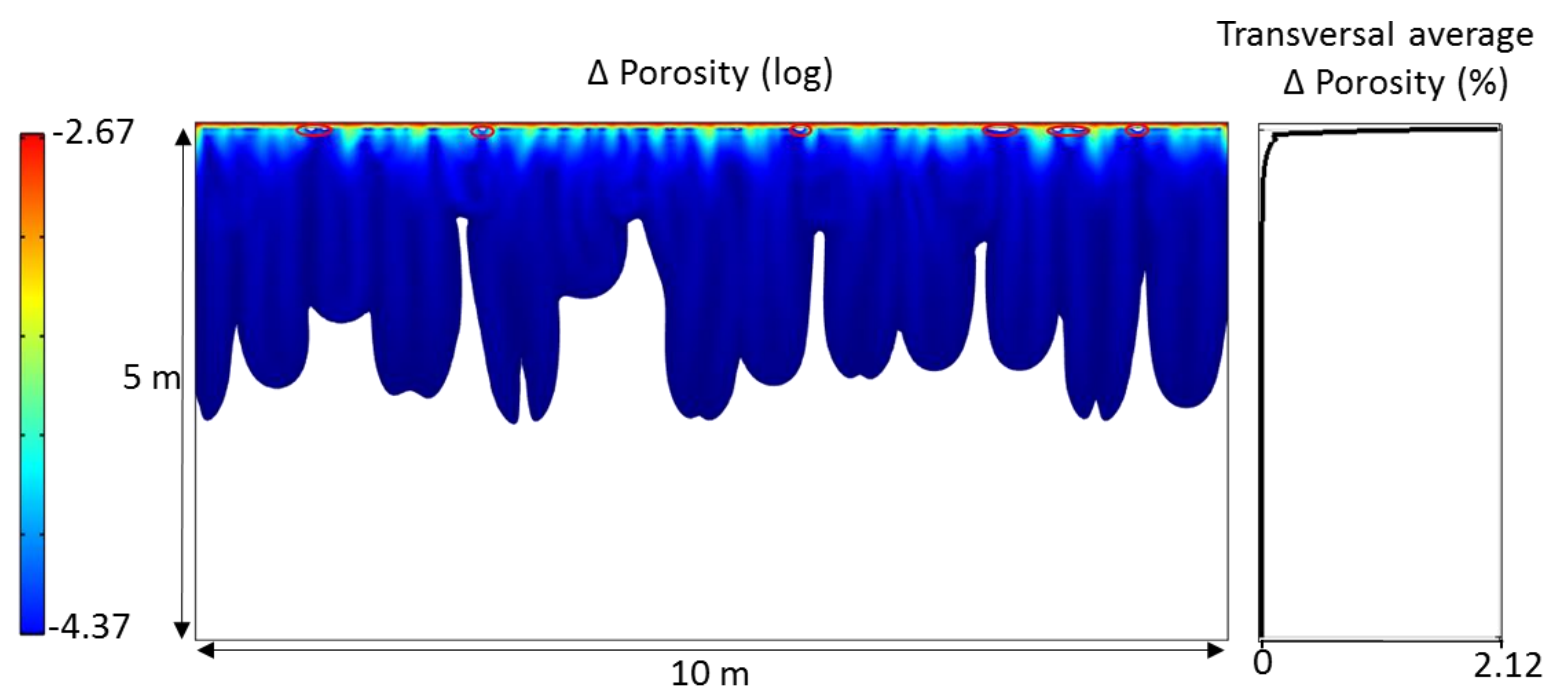

Fig. 5. Logarithm of porosity increase (left) and horizontal average percentage of porosity variation (right) for the RaHDaM simulation after one year. Areas with no increase are shown in white. The red circles close to the top indicate areas of porosity loss due to gypsum precipitation. 

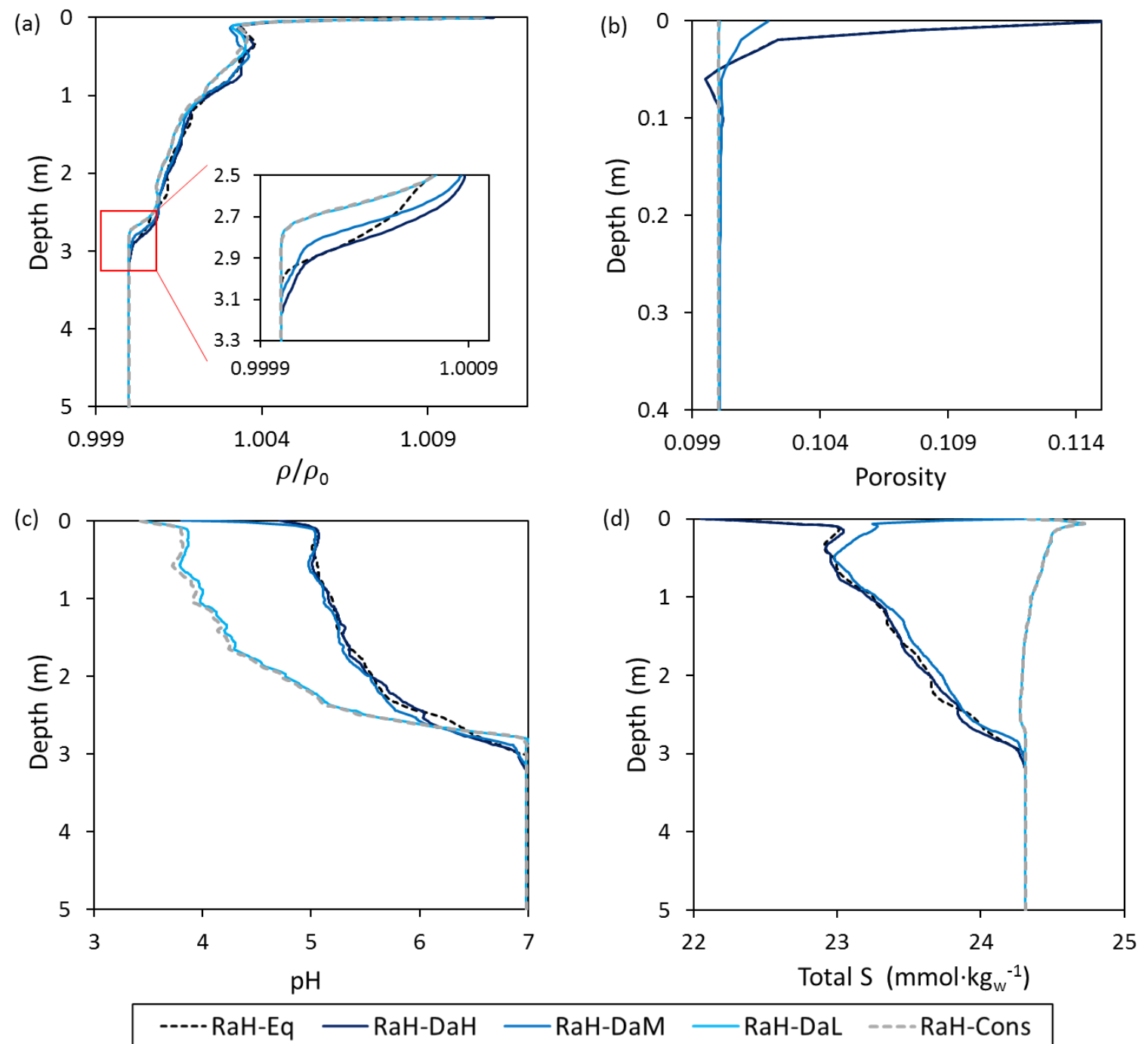

Fig. 6. Vertical profile of spatially averaged density (a), porosity (b), $\mathrm{pH}(\mathrm{d})$ and aqueous sulphur (d) for simulations with equal Rayleigh (3600) and different reactivity: high, medium and low Damköhler numbers (RaH-DaH, RaH-DaM and RaH$\mathrm{DaL}$ ), calcite in equilibrium ( $\mathrm{RaH}-\mathrm{Eq}$ ) and conservative case (RaH-Cons); after one year of simulation. An inset in a shows a detail of the vertical profiles. Note the different units and vertical scales in $b$. 

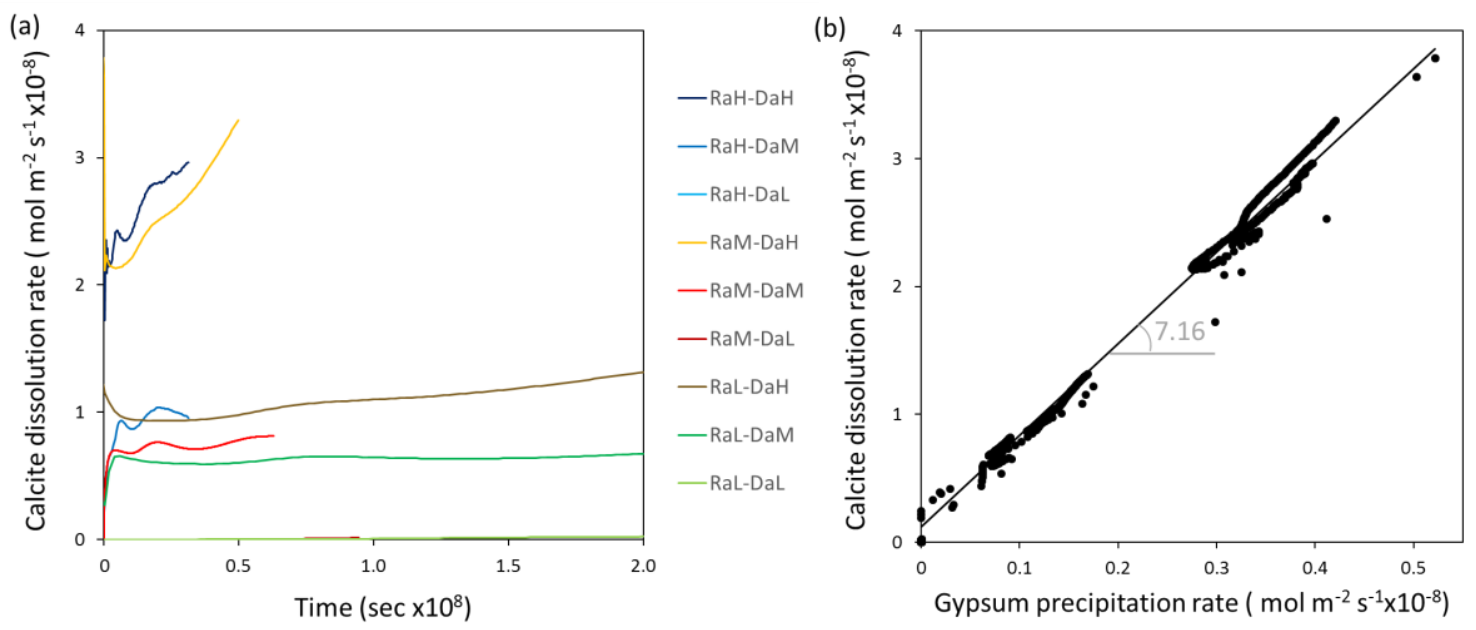

Fig. 7. Time evolution of calcite dissolution rates (a) and calcite dissolution rates versus gypsum precipitation rates (b) for all simulations.. RaH, RaM and RaL refer to high, medium and low Rayleigh numbers; DaH, DaM and DaL stand for high, medium and low Damköhler numbers - see Table 3. Simulations with low Da (around $1.85 \times 10^{4}$ ) are difficult to distinguish in (a) due to their small dissolution flux. The slope of the linear regression between calcite dissolution and gypsum precipitation is plotted in (b). 
(a)

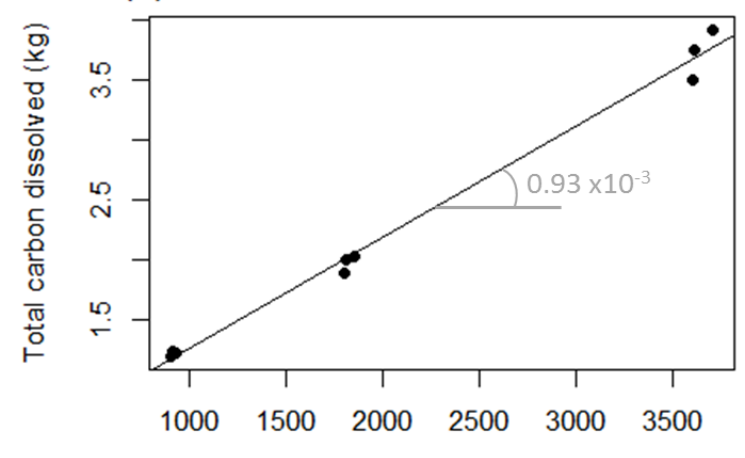

$\mathrm{Ra}$

(c)

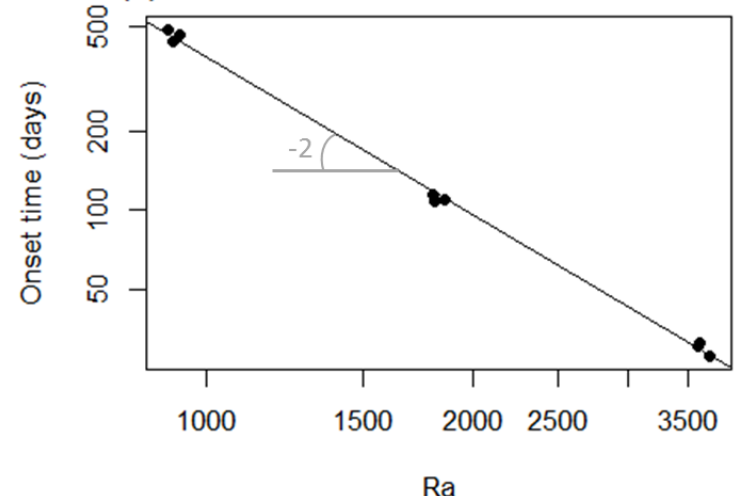

(b)

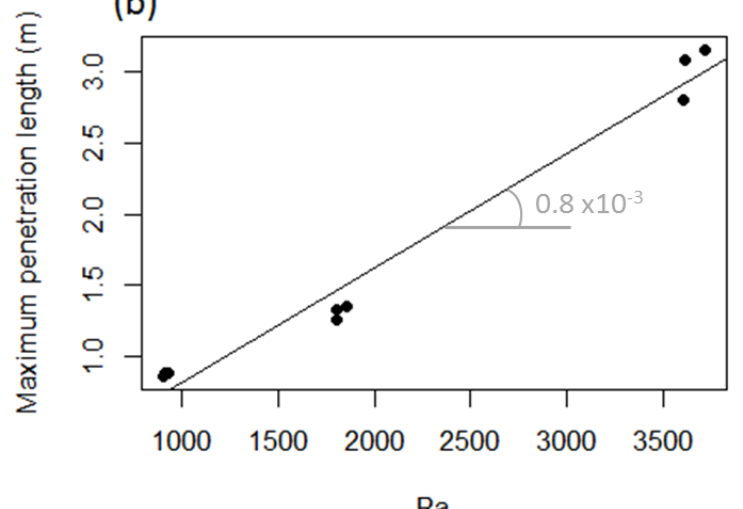

(d)

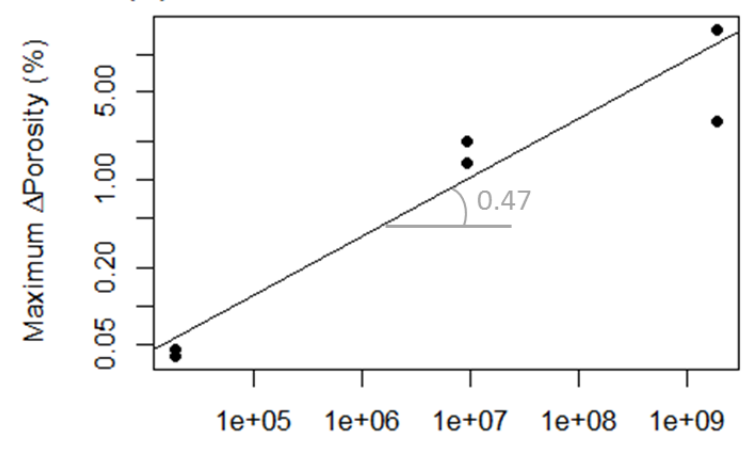

Da

Fig. 8. Total dissolved carbon (a), maximum downward penetration of fingers (b) and time of convection onset (c) versus Rayleigh number; and maximum porosity development (d) versus Damköhler number for all simulations after one year. In (d) values from simulations with high and medium Da are overlapped. Note the log scales in (c) and (d). The slopes of the linear regression between the axes are plotted in the figures. 


\section{Tables}

Table 1

Chemistry of the two end-member fluids at $80^{\circ} \mathrm{C}$. Concentration in $\mathrm{mmol} \cdot \mathrm{kg}_{\mathrm{w}}{ }^{-1}$. Density is given in $\mathrm{kg} \cdot \mathrm{m}^{-3}$.

\begin{tabular}{lcccccccccccc}
\hline & Density & $\mathrm{pH}$ & $\mathrm{C}$ & $\mathrm{B}$ & $\mathrm{Br}$ & $\mathrm{Ca}$ & $\mathrm{Cl}$ & $\mathrm{F}$ & $\mathrm{K}$ & $\mathrm{Mg}$ & $\mathrm{Na}$ & $\mathrm{S}$ \\
\hline Native fluid & 1024.5 & 6.98 & 0.263 & 1.465 & 1.036 & 53.51 & 547.1 & 0.19 & 14.34 & 2.623 & 470.7 & 24.31 \\
$\mathrm{CO}_{2}$-rich fluid & 1035.9 & 3.35 & 652.3 & 1.465 & 1.036 & 53.51 & 547.1 & 0.19 & 14.34 & 2.623 & 470.7 & 24.31 \\
\hline
\end{tabular}

Table 2

Model parameters. The calcite dissolution rate equation is taken from Plummer et al. (1978), where $k_{1}, k_{2}$ and $k_{3}$ are detailed. This equation is already implemented in the IInl database (Delany and Lundeen, 1990). $a_{\mathrm{H}^{+}}, a_{\mathrm{CO}_{2}}$ and $a_{\mathrm{H}_{2} \mathrm{O}}$ correspond to the activity of protons, aqueous $\mathrm{CO}_{2}$ and water respectively.

\begin{tabular}{|c|c|c|c|}
\hline Parameter & Symbol & Value & Units \\
\hline Dynamic viscosity & $\mu$ & $5 \times 10^{-4}$ & $\mathrm{~Pa} \cdot \mathrm{S}$ \\
\hline Specific storativity & $S_{S}$ & $1.02 \times 10^{-8}$ & $\mathrm{~Pa}^{-1}$ \\
\hline Temperature & $T$ & 80 & ${ }^{\circ} \mathrm{C}$ \\
\hline Molecular diffusion coefficient & $D_{m}$ & $1 \times 10^{-9}$ & $\mathrm{~m}^{2} \cdot \mathrm{s}^{-1}$ \\
\hline Initial porosity & $\phi_{0}$ & 0.1 & - \\
\hline Initial fluid density & $\rho_{0}$ & 1024.5 & $\mathrm{~kg} \cdot \mathrm{m}^{-3}$ \\
\hline Compressibility factor & $\beta$ & 17 & $\mathrm{~kg} \cdot \mathrm{mol}^{-1}$ \\
\hline Volume ratio of inert minerals & $\phi_{\text {inert }}$ & 0.85 & - \\
\hline Initial permeability & $\kappa$ & $8.32 \times 10^{-14}-1.66 \times 10^{-13}-3.33 \times 10^{-13}$ & $m^{2}$ \\
\hline Specific surface area & $a$ & $7.38 \times 10^{-3}-3.69 \times 10^{-5}-7.38 \times 10^{-8}$ & $\mathrm{~cm}^{2} \cdot \mathrm{gr}^{-1}$ \\
\hline Initial amount of calcite & $m_{0}$ & 1.354 & $\mathrm{~mol} \cdot \mathrm{m}^{-3}$ media \\
\hline Exponent factor & $\omega$ & 0.6 & - \\
\hline \multirow[t]{4}{*}{ Calcite kinetic constant rate } & $k_{r}$ & $k_{1} a_{\mathrm{H}^{+}}+k_{2} a_{\mathrm{CO}_{2}}+k_{3} a_{\mathrm{H}_{2} \mathrm{O}}$ & $\mathrm{mol} \cdot \mathrm{cm}^{-2} \cdot \mathrm{s}^{-1}$ \\
\hline & $k_{1}$ & $8.73 \times 10^{-2}$ & - \\
\hline & $k_{2}$ & $4.74 \times 10^{-4}$ & - \\
\hline & $k_{3}$ & $9.58 \times 10^{-7}$ & - \\
\hline
\end{tabular}


Table 3

Description of Rayleigh and Damköhler numbers of various model simulations. $\mathrm{H}=\mathrm{High}, \mathrm{M}=$ Medium and $\mathrm{L}=$ low.

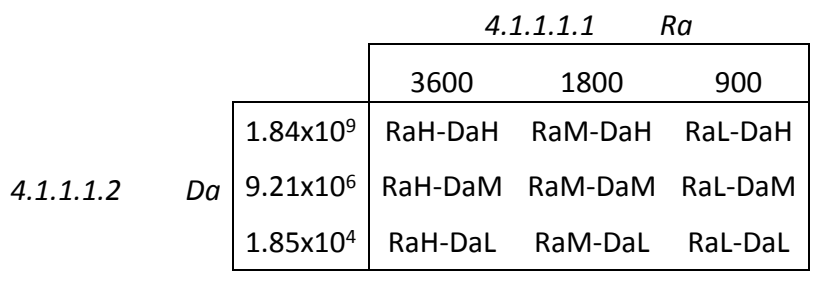

